\title{
Early ischemic preconditioning without hypotension prevents spinal cord injury caused by descending thoracic aortic occlusion
}

Ioannis K. Toumpoulis, MD, ${ }^{\text {a } C o n s t a n t i n e ~ E . ~ A n a g n o s t o p o u l o s, ~ M D, ~}{ }^{\mathrm{a}, \mathrm{c}}$ George E. Drossos, MD, ${ }^{\mathrm{a}}$

Vassiliki D. Malamou-Mitsi, MD, ${ }^{\mathrm{b}}$ Lina S. Pappa, MD, ${ }^{\mathrm{b}}$ and Demosthenes G. Katritsis, MD ${ }^{\mathrm{a}}$

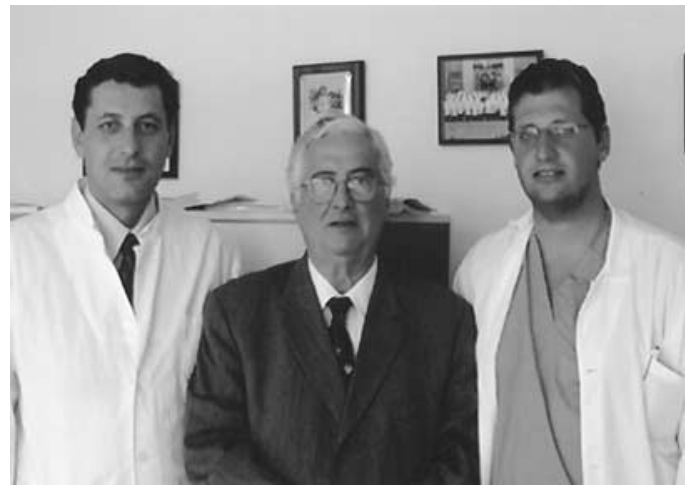

Drossos, Anagnostopoulos, Toumpoulis (left to right)
Objective: Postoperative neurologic deficits after thoracic aortic reconstruction vary widely. Our previous study showed that delayed ischemic preconditioning could prevent spinal cord injury caused by occlusion of the descending thoracic aorta in pigs. We investigated early ischemic preconditioning in the same model.

Methods: Twenty-eight pigs were divided into 4 groups: group $1(\mathrm{n}=6)$ underwent a sham operation, group $2(\mathrm{n}=6)$ underwent aortic occlusion for 20 minutes, group $3(\mathrm{n}=8)$ underwent aortic occlusion for 35 minutes, and group $4(\mathrm{n}=8)$ underwent aortic occlusion for 20 minutes and underwent aortic occlusion 80 minutes later without hypotension for 35 minutes. Aortic occlusion was accomplished by using 2 balloon occlusion catheters placed fluoroscopically at T6 to T8 above the diaphragm and at the aortic bifurcation. Neurologic evaluation was performed by an independent observer according to the Tarlov scale (0-4). The lower thoracic and lumbar spinal cords were harvested at 120 hours and examined histologically with hematoxylin-and-eosin stain. Histologic results (number of neurons and grade of inflammation) were scored (0-4) and were similarly analyzed. Statistical analysis was by means of the Kruskal-Wallis test.

Results: Group 4 had a better neurologic outcome at 24, 48, and 120 hours in comparison with group $3(P<.001)$. The histologic changes were proportional to the neurologic test scores, with the more severe and extensive gray matter damage in animals of group 3 (number of neurons, $P<.001$; grade of inflammation, $P<$ $.001)$.

Conclusion: Early ischemic preconditioning without hypotension protects against spinal cord injury after aortic occlusion, as confirmed by using the Tarlov score and histopathology.

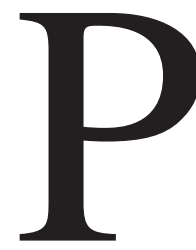
ostoperative neurologic deficits after thoracic aortic reconstruction vary widely. The incidence of neurologic impairment might be as high as $5 \%$ to $40 \%$ of patients in certain subgroups. ${ }^{1-3}$ Paraplegia is most likely to occur after the reconstruction of the peridiaphragmatic aorta, from which radicular spinal cord vessels might arise, and usually, once it occurs, it is irreversible. The cause of spastic paraplegiaparaparesis after descending thoracic or thoracoabdominal aortic surgery is thought to be multifactorial and remains one of the most devastating complications both for the patient and the surgeon.

A number of techniques and drugs that might reduce the ischemia-reperfusion injury of the spinal cord have been tried both clinically and experimentally, with varying success. Adjuncts that have been investigated include distal aortic perfu- 
TABLE 1. Criteria used for scoring the number of motor neurons, the grade of inflammation, and the neurologic outcome

\begin{tabular}{|c|c|c|c|}
\hline & Score of neurons & Grade of inflammation & Tarlov score \\
\hline Score 0 & $<50$ & $\begin{array}{l}\text { Very high grade of inflammation with very high vascularization } \\
\text { with hyperemia and very high grade of vacuolization of the } \\
\text { gray matter }\end{array}$ & $\begin{array}{l}\text { Spastic paraplegia and no } \\
\text { movement of the lower limbs }\end{array}$ \\
\hline Score 1 & $51-70$ & $\begin{array}{l}\text { High grade of inflammation with high vascularization with } \\
\text { hyperemia and high grade of vacuolization of the gray matter }\end{array}$ & $\begin{array}{l}\text { Spastic paraplegia and slight } \\
\text { movement of the lower limbs }\end{array}$ \\
\hline Score 2 & $71-90$ & $\begin{array}{l}\text { Moderate-grade inflammation with moderate vascularization } \\
\text { with or without hyperemia and moderate or low vacuolization } \\
\text { of the gray matter }\end{array}$ & $\begin{array}{l}\text { Good movement of the lower } \\
\text { limbs but unable to stand }\end{array}$ \\
\hline Score 3 & $91-110$ & $\begin{array}{l}\text { Low-grade inflammation with moderate vascularization with or } \\
\text { without hyperemia and no vacuolization of the gray matter }\end{array}$ & $\begin{array}{l}\text { Able to stand but unable to } \\
\text { walk normally }\end{array}$ \\
\hline Score 4 & $>110$ & $\begin{array}{l}\text { No inflammation with normal vascularization without hyperemia } \\
\text { and no vacuolization of the gray matter }\end{array}$ & $\begin{array}{l}\text { Complete recovery and normal } \\
\text { gait-hopping }\end{array}$ \\
\hline
\end{tabular}

The classification of the score of neurons was constructed to be in accordance with the observed Tarlov scores.

sion, reattachment of critical intercostal arteries, cerebrospinal fluid drainage, regional hypothermia, and pharmacologic agents (eg, steroids, superoxide dismutase, naloxone, excitatory amino acids antagonists, adenosine, and adenosine agonists). ${ }^{4-13}$ However, no reliable method has been developed that totally prevents paraplegia.

In the past 15 years, there was systematic research on the protection provided by ischemic preconditioning (IPC) after irreversible ischemia, especially in the myocardium. Since the advent of IPC in the myocardium by Murry and colleagues, ${ }^{14}$ the application of IPC in other organs is also undergoing experimental research. ${ }^{15}$ Recently, there is experimental evidence that IPC protects against ischemic spinal cord injury in small-animal models, ${ }^{16,17}$ but the exact time of protection is still an issue to be elucidated.

IPC is the process whereby a brief period of nonlethal ischemia increases the tolerance of the tissue to a subsequent lethal ischemia. IPC is an endogenous cellular protective mechanism that was subsequently found to be a biphasic phenomenon, with an early and a late phase of protection. ${ }^{16,18-20}$ The aim of this study is to investigate whether IPC, especially the early phase, provides a beneficial effect on ischemic spinal cord injury of supraceliac descending thoracic aortic occlusion (AOC) in a largemammal animal model. To date, we know of no published studies of a short reperfusion interval in a large-mammal animal model of spinal cord ischemia. We hypothesized that IPC of the porcine spinal cord by means of AOC would reduce neurologic deficit and that the mechanisms of IPC protection can be acutely invoked by an 80-minute reperfusion interval between the IPC and the prolonged ischemic insult.

\section{Materials and Methods Experimental Protocol}

A total of 28 pigs of either sex were used in this study. All animals weighed between 27 and $31 \mathrm{~kg}$ and were randomly assigned to one of 4 groups. Group $1(n=6)$ underwent a sham operation, group $2(\mathrm{n}=6)$ underwent AOC for 20 minutes, group $3(\mathrm{n}=8)$ underwent AOC for 35 minutes, and group $4(\mathrm{n}=8)$ underwent AOC for 20 minutes and underwent AOC 80 minutes later for 35 minutes. All animals received humane care in compliance with the "Guide for the Care and Use of Laboratory Animals" published by the National Institutes of Health 5377-3 (National Academy Press, 1996), and the animal protocol was approved by the Institutional Animal Care and Use Committee of the University of Ioannina, Greece.

\section{Experimental Preparation}

As described in our previous study, ${ }^{20}$ the pigs were anesthetized with intramuscular injection of azaperone $(4 \mathrm{mg} / \mathrm{kg})$ and, after 20 minutes, ketamine $(5-10 \mathrm{mg} / \mathrm{kg})$. Catheters were placed in 2 ear veins for intravenous administration of general anesthesia and fluids. General anesthesia consisted of $2.5 \%$ thiopental in a dose of 10 to $15 \mathrm{mg} / \mathrm{kg}$, and the animals were tracheally intubated and given intravenous ketamine $(1-2 \mathrm{mg} / \mathrm{kg})$, atracurium $(0.4-0.6$ $\mathrm{mg} / \mathrm{kg}$ and $0.1 \mathrm{mg} / \mathrm{kg}$ every 20-30 minutes), fentanyl (1.5-8 $\mu \mathrm{g} /$ $\mathrm{kg}$ ), and gentamicin sulfate $(1 \mathrm{mg} / \mathrm{kg})$. General anesthesia was maintained with $1 \%$ to $4 \%$ sevoflurane depending on the phase of the experiment. The pigs' lungs were ventilated with $100 \%$ oxygen, with the arterial $\mathrm{PaO}_{2}$ maintained at greater than $100 \mathrm{~mm} \mathrm{Hg}$, $\mathrm{PaCO}_{2}$ maintained at 35 to $45 \mathrm{~mm} \mathrm{Hg}$, and $\mathrm{pH}$ at normal levels, as confirmed by means of arterial blood gas analysis. All animals were placed on a warming blanket, and rectal temperature was maintained at $35.9^{\circ} \mathrm{C}$ to $36.7^{\circ} \mathrm{C}$. Electrocardiograms were continuously recorded with needle electrodes.

Under sterile conditions, the right femoral artery, left jugular vein, and left common carotid artery were isolated, and after the administration of intravenous heparin (300 UI/ $\mathrm{kg}$ ), catheters were inserted. Continuous monitoring of the proximal and distal, as well as pulmonary, arterial blood pressure was recorded. Systolic blood pressure was maintained at greater than $100 \mathrm{~mm} \mathrm{Hg}$, and blood (7 $\mathrm{mL} / \mathrm{kg}$ ) was drained into a citrate bag.

In this experimental model the AOC was performed with two 9F aortic balloon occlusion catheters (Occlusion Balloon Catheters, Medi-tech Boston Scientific), which were inserted with fluoroscopic guidance. The first was inserted through the carotid 
TABLE 2. Proximal and distal systolic arterial blood pressure, rectal temperature, and heart rate at baseline, during AOC, and during reperfusion

\begin{tabular}{|c|c|c|c|c|c|c|}
\hline & \multicolumn{4}{|c|}{ Baseline } & \multicolumn{2}{|r|}{ First } \\
\hline & $\begin{array}{c}\text { Proximal SAP, } \\
(\mathrm{mm} \mathrm{Hg})\end{array}$ & $\begin{array}{c}\text { Distal SAP } \\
\text { (mm Hg) }\end{array}$ & $\begin{array}{c}\text { Temprature } \\
\left({ }^{\circ} \mathrm{C}\right)\end{array}$ & $\begin{array}{l}\text { Heart rate } \\
\text { (beats/min) }\end{array}$ & $\begin{array}{c}\text { Proximal SAP } \\
(\mathrm{mm} \mathrm{Hg})\end{array}$ & $\begin{array}{c}\text { Distal SAP } \\
(\mathrm{mm} \mathrm{Hg})\end{array}$ \\
\hline Group 1 (no AOC) & $108 \pm 3$ & $111 \pm 5$ & $36.6 \pm 0.3$ & $94 \pm 10$ & $109 \pm 6$ & $111 \pm 5$ \\
\hline Group 2 & $108 \pm 6$ & $109 \pm 5$ & $36.7 \pm 0.2$ & $86 \pm 32$ & $178 \pm 8$ & $12 \pm 1$ \\
\hline Group 3 & $114 \pm 6$ & $112 \pm 8$ & $36.5 \pm 0.3$ & $98 \pm 16$ & $180 \pm 8$ & $12 \pm 2$ \\
\hline Group 4 (first $A O C$ ) & $107 \pm 5$ & $111 \pm 4$ & $36.7 \pm 0.2$ & $93 \pm 9$ & $176 \pm 8$ & $12 \pm 2$ \\
\hline$P$ value & $P=.057$ & $P=.843$ & $P=.191$ & $P=.688$ & $P<.001$ & $P<.001$ \\
\hline
\end{tabular}

Data are expressed as means $\pm S D$, and statistical analysis was by means of 1-way analysis of variance.

$S A P$, Systolic arterial blood pressure; AISP, aortic isolated segment pressure.

artery to the supraceliac aorta and pulled up toward the carotid artery to achieve thoracic AOC between T6 and T8 and entirely above the diaphragm when inflated. The second balloon was inserted through the femoral artery to the aortic bifurcation and the common iliac arteries (to avoid retrograde flow). During AOC and 1 hour after the blood flow restoration, the heart rate, arterial blood pressure (proximal, aortic isolated segment, and distal), and rectal temperature were recorded every 5 minutes. After AOC (in groups 2, 3, and 4), the balloons deflated, and all animals were fully resuscitated with intravenous fluids (Lactated Ringer solution) and the reinfusion of autologous blood. Sodium bicarbonate $(1 \mathrm{mEq} /$ $\mathrm{kg}$ ) was administered to restore acid-base status, and blood pressure was restored with phenylephrine hydrochloride (0.1-0.2 mg in bolus infusion during the first minutes after blood flow restoration). After 60 minutes of reperfusion, all the animals were hemodynamically stable (systolic blood pressure $>105 \mathrm{~mm} \mathrm{Hg}$ ), without the need of fluid or drug administration. All the catheters were removed, and all wounds were closed. When the pig was breathing spontaneously, the trachea was extubated, and another dose of gentamicin sulfate $(1 \mathrm{mg} / \mathrm{kg})$ was administered intravenously. Finally, the animals were placed in their cages for postoperative care.

Animals in group 1 (sham operation) underwent the above procedure, but the balloons were not inflated. In group 2 there was inflation for 20 minutes only, and in group 3 there was inflation for 35 minutes without IPC. In group 4 we performed 2 AOCs with an interval of 80 minutes between them. Before each AOC, blood was taken from the animals for the 2 autologous reinfusions. During the reperfusion interval of 80 minutes, we maintained the systolic arterial blood pressure at greater than $100 \mathrm{~mm} \mathrm{Hg}$.

\section{Neurologic Evaluation}

Twenty-four, 48, and 120 hours after the end of the experiment, all animals were evaluated by an independent observer according to the Tarlov scoring system (Table 1). ${ }^{21}$

\section{Histologic Study}

The animals were killed 120 hours after the end of the experiment with an overdose injection of sodium pentobarbital, whereas spinal cord specimens were harvested immediately for histologic study by means of light microscopy. The lower thoracic and lumbar spinal cords were fixed in $10 \%$ formalin solution for 120 hours before being set in paraffin blocks for sectioning. Three representative glass slices with $7-\mu \mathrm{m}$-thick sections were obtained from each animal and stained with hematoxylin and eosin. A pathologist unaware of the pig's neurologic outcome examined each slice by means of light microscopy to count the total number of motor neurons in the half gray matter of each slice. The number of motor neurons and the grade of inflammation were scored from 0 to 4 according to the criteria of Table 1 .

\section{Statistical Analysis}

Data are presented as means $\pm \mathrm{SD}$ or means $\pm \mathrm{SEM}$, as noted in each table. Statistical evaluation was performed by means of 1-way analysis of variance test with the post hoc Tukey honestly significant difference test for comparison of experimental variables between groups. The comparison of experimental variables within a group was by means of the paired-samples $t$ test, and that between 2 groups was by means of the independent-samples $t$ test. The difference among groups in terms of Tarlov scores, scored neurons, and grade of inflammation was determined by means of nonparametric statistical analysis with the Kruskal-Wallis test. $P$ values were determined with SPSS 8.0 Software (SPSS Inc, Chicago, Ill), and all $P$ values are 2 tailed.

\section{Results}

\section{Hemodynamic Measurements}

The animals did not differ with respect to blood gas analysis. There was no significant difference between groups 2 , 3 , and 4 with regard to proximal and distal systolic arterial pressure, rectal temperature, and heart rate at baseline, during AOC, and during reperfusion. Between group 1 and groups 2, 3, and 4, there was a significant difference in heart rate and proximal and distal systolic arterial pressure during the AOC (Table 2). The systolic arterial pressure proximal to AOC and the heart rate in the early IPC group 4 were significantly decreased during the second AOC of 35 minutes in comparison with the first AOC of 20 minutes (Table 3 ) or in comparison with the AOC of 35 minutes of the untreated group $3(P<.001$, independent-samples $t$ test). There was no significant difference in aortic isolated segment pressure in groups 2, 3, and 4, as seen in Table 2.

Two additional animals treated with early IPC were excluded from the study because during the 80-minute interval of reperfusion between the 2 AOCs, the systolic 


\begin{tabular}{|c|c|c|c|c|c|c|}
\hline \multicolumn{3}{|c|}{$\mathrm{AOC}$} & \multicolumn{4}{|c|}{ Reperfusion } \\
\hline $\begin{array}{c}\text { AISP } \\
(\mathrm{mm} \mathrm{Hg})\end{array}$ & $\begin{array}{c}\text { Temperture } \\
\left({ }^{\circ} \mathrm{C}\right)\end{array}$ & $\begin{array}{l}\text { Heart rate } \\
\text { (beats/min) }\end{array}$ & $\begin{array}{c}\text { Proximal SAP } \\
(\mathrm{mm} \mathrm{Hg})\end{array}$ & $\begin{array}{c}\text { Distal SAP } \\
(\mathrm{mm} \mathrm{Hg})\end{array}$ & $\begin{array}{c}\text { Temperture } \\
\left({ }^{\circ} \mathrm{C}\right)\end{array}$ & $\begin{array}{l}\text { Heart rate } \\
\text { (beats/min) }\end{array}$ \\
\hline -- & $36.3 \pm 0.2$ & $103 \pm 11$ & $108 \pm 4$ & $110 \pm 5$ & $36.2 \pm 0.3$ & $111 \pm 15$ \\
\hline $14 \pm 2$ & $36.3 \pm 0.2$ & $179 \pm 17$ & $110 \pm 7$ & $108 \pm 9$ & $36.3 \pm 0.2$ & $115 \pm 23$ \\
\hline $14 \pm 2$ & $36.2 \pm 0.3$ & $172 \pm 15$ & $108 \pm 8$ & $107 \pm 9$ & $36.1 \pm 0.2$ & $117 \pm 19$ \\
\hline $14 \pm 3$ & $36.3 \pm 0.2$ & $170 \pm 13$ & $110 \pm 7$ & $108 \pm 8$ & $36.2 \pm 0.2$ & $120 \pm 19$ \\
\hline$P=.116$ & $P=.352$ & $P<.001$ & $P=.531$ & $P=.612$ & $P=.132$ & $P=.250$ \\
\hline
\end{tabular}

TABLE 3. Proximal systolic arterial blood pressure and heart rate at baseline, during AOC, and during reperfusion in group 4 during the first AOC (20 minutes) and the second AOC (35 minutes)

\begin{tabular}{|c|c|c|c|c|c|c|}
\hline & \multicolumn{2}{|c|}{ Baseline } & \multicolumn{2}{|c|}{ Aortic occlusion } & \multicolumn{2}{|c|}{ Reperfusion } \\
\hline & $\begin{array}{c}\text { Proximal SAP } \\
(\mathrm{mm} \mathrm{Hg})\end{array}$ & $\begin{array}{l}\text { Heart rate } \\
\text { (beats/min) }\end{array}$ & $\begin{array}{c}\text { Proximal SAP } \\
(\mathbf{m m ~ H g})\end{array}$ & $\begin{array}{l}\text { Heart rate } \\
\text { (beats/min) }\end{array}$ & $\begin{array}{c}\text { Proximal SAP } \\
(\mathrm{mm} \mathrm{Hg})\end{array}$ & $\begin{array}{c}\text { Heart rate } \\
\text { (beats/min) }\end{array}$ \\
\hline Group 4 First AOC (20 min) & $108 \pm 5$ & $93 \pm 9$ & $176 \pm 8$ & $170 \pm 13$ & $110 \pm 7$ & $120 \pm 19$ \\
\hline Group 4 Second AOC (35 min) & $109 \pm 6$ & $99 \pm 6$ & $156 \pm 11$ & $156 \pm 21$ & $110 \pm 7$ & $122 \pm 13$ \\
\hline$P$ value & $P=.539$ & $P=.175$ & $P<.001$ & $P=.001$ & $P=.700$ & $P=.654$ \\
\hline
\end{tabular}

Data are expressed as means $\pm \mathrm{SD}$, and statistical analysis was by means of paired-samples $t$ test.

$S A P$, Systolic arterial blood pressure.

TABLE 4. Tarlov scores at 24,48 , and 120 hours after the end of the experiment

\begin{tabular}{|c|c|c|c|}
\hline & $24 \mathrm{~h}$ & $48 \mathrm{~h}$ & $120 \mathrm{~h}$ \\
\hline Group 1 ( $n=6$ ) (sham operation) & $4.0 \pm 0.0$ & $4.0 \pm 0.0$ & $4.0 \pm 0.0$ \\
\hline Group $2(n=6)(20 \min A O C)$ & $4.0 \pm 0.0$ & $4.0 \pm 0.0$ & $4.0 \pm 0.0$ \\
\hline Group $3(n=8)(35 \min A O C)$ & $2.1 \pm 0.2$ & $2.0 \pm 0.2$ & $1.8 \pm 0.2$ \\
\hline Group 4 (n = 8) (early IPC) & $4.0 \pm 0.0$ & $4.0 \pm 0.0$ & $4.0 \pm 0.0$ \\
\hline$P$ value & $P<.001$ & $P<.001$ & $P<.001$ \\
\hline
\end{tabular}

Data are expressed as means \pm SEM, and statistical analysis was by means of the nonparametric Kruskal-Wallis test.

arterial pressure was low (80-90 mm Hg). The second AOC took place nevertheless, even though it was outside protocol, and these animals, although initially normal, had a Tarlov score of 2 at 48 hours.

\section{Neurologic Outcome}

The results are summarized in Table 4. All animals in group $1(n=6)$, group $2(n=6)$, and group $4(n=8)$ had normal neurologic outcomes (Tarlov score of 4) at 24, 48, and 120 hours.

In group $3(\mathrm{n}=8)$ at 24 hours, $2(25 \%)$ animals had Tarlov scores of 3, 5 (62.5\%) animals had scores of 2, and $1(12.5 \%)$ animal had a score of 1 . At 48 hours, 1 (12.5\%)
TABLE 5. Number of motor neurons in half gray matter, score of neurons, and grade of inflammation

\begin{tabular}{lccc}
\hline & $\begin{array}{c}\text { No. of } \\
\text { neurons }\end{array}$ & $\begin{array}{c}\text { Score of } \\
\text { neurons }\end{array}$ & $\begin{array}{c}\text { Grade of } \\
\text { inflammation }\end{array}$ \\
\hline $\begin{array}{l}\text { Group } 1(\mathrm{n}=6) \text { (sham } \\
\quad \text { operation) }\end{array}$ & $178 \pm 7$ & $4.0 \pm 0.0$ & $4.0 \pm 0.0$ \\
Group 2 $(\mathrm{n}=6)(20 \mathrm{~min}$ AOC) & $175 \pm 9$ & $4.0 \pm 0.0$ & $4.0 \pm 0.0$ \\
Group 3 $(\mathrm{n}=8)(35 \mathrm{~min} A O C)$ & $74 \pm 9$ & $1.8 \pm 0.2$ & $1.6 \pm 0.4$ \\
Group 4 $(\mathrm{n}=8)$ (early IPC) & $157 \pm 24$ & $3.9 \pm 0.1$ & $3.8 \pm 0.2$ \\
P value & $P<.001$ & $P<.001$ & $P<.001$
\end{tabular}

Data are expressed as means \pm SEM, except number of neurons (mean \pm $\mathrm{SD}$ ), and statistical analysis was by means of 1-way analysis of variance test for the number of motor neurons and nonparametric Kruskal-Wallis test for the grade of inflammation and score of neurons.

animal had a score of 3, $6(75 \%)$ animals had scores of 2, and $1(12.5 \%)$ animal had a score of 1 , and at 120 hours, 6 (75\%) animals had scores of 2 , and $2(25 \%)$ animals had scores of 1 .

A significant difference was seen in neurologic outcome between group 3 and groups 1, 2, and 4 at 24, 48, and 120 hours $(P<.001)$. There was an aggravation of the mean Tarlov scores in group 3 comparing the results at 24 and 120 hours after the end of the experiment, but this aggravation was not statistically significant $(P=.083$, Wilcoxon test). 
If intention to treat is followed and all 10 animals are included in group 4, the 24-, 48-, and 120-hour Tarlov score difference in favor of group 4 is still statistically significant (4.00 vs $2.13[P<.001], 3.60$ vs $2.00[P=.002]$, and 3.60 vs $1.75[P=.001]$, respectively; Mann-Whitney $U$ test).

\section{Histologic Evaluation}

The results of neuron counting in the half gray matter region of each slice are shown in Table 5. According to the scoring system noted in Table 1, animals in group 3 had the worst score $(74 \pm 9$ motor neurons, $1.63 \pm 0.42$ inflammation score, and $1.75 \pm 0.16$ neuron score) in comparison with animals in group $1(178 \pm 7$ motor neurons, $4.00 \pm 0.00$ inflammation score, and $4.00 \pm 0.00$ neuron score), group 2 (175 \pm 9 motor neurons, $4.00 \pm 0.00$ inflammation score, and $4.00 \pm 0.00$ neuron score), and group 4 (157 \pm 24 motor neurons, $3.75 \pm 0.16$ inflammation score, and $3.88 \pm$ 0.13 neuron score), and these differences were statistically significant $(P<.001)$. A reduction of approximately $12 \%$ in the number of neurons, which was observed in early IPC group 4, was not statistically significant in comparison with numbers seen in group $1(P=.06)$ and group $2(P=.134)$ in post hoc multiple comparisons tests that used the Tukey honestly significant difference. Representative photographs of spinal cord sections are shown in Figure 1.

\section{Discussion}

Previous reports in small-animal models have shown a beneficial effect of early IPC against spinal cord injury. Fan and colleagues, ${ }^{22}$ using a rabbit model, were the first to evaluate the effect of early IPC in the spinal cord. After 5 minutes of IPC with an interval of 20 minutes of reperfusion, the descending thoracic aorta occluded for 30 minutes. They found a reduction in the release of the monoamines norepinephrine and serotonin, and this correlated with an improved spinal cord blood flow and improved spinal cord evoked potentials. However, they had no evaluation of the neurologic outcome or histologic morphology of the spinal cord. Zvara and coworkers, ${ }^{17}$ using a rat model, studied early IPC by using 3 minutes of IPC 30 minutes before 12 minutes of ischemia caused by descending thoracic AOC. They evaluated the neurologic outcome 24 and 48 hours after the ischemic insult, as well as spinal cord specimens stained by using the hematoxylin-and-eosin method. They conclude that early IPC reduces neurologic injury, and the results of the histologic evaluation were consistent with the neurologic scores. Ueno and associates, ${ }^{23}$ using a rabbit model, studied early IPC, trying 3 minutes of IPC with 3 minutes of reperfusion twice before 15 minutes of infrarenal aortic crossclamping. They found a significantly greater increase in lumbar spinal cord blood flow, and although IPC did not significantly improve overall neurologic status, it contributed to lower incidence of spastic paraplegia.
The exact mechanism of protection afforded by means of early IPC is not clearly understood. However, many studies support a role for adenosine as an initiator of early IPC. Levels of this purine nucleoside increase during the periods of preconditioning ischemia and activate $\mathrm{A}_{1}$ and $\mathrm{A}_{3}$ receptors. This might increase the activity of phospholipases $\mathrm{C}$, $\mathrm{D}$, or both, which increase the formation of diacylglycerol, which in turn promotes the translocation of specific isoforms of protein kinase $\mathrm{C}$ to cell membranes. Protein kinase $\mathrm{C}$ and activated tyrosine kinases stimulate the effector proteins of early IPC, which are potassium adenosine triphosphate $\left(\mathrm{K}_{\mathrm{ATP}}\right)$ channels, 5'-nucleotidase translocation, and others. ${ }^{18,19}$ The mechanism by which $\mathrm{K}_{\text {ATP }}$ channel activation contributes to the preconditioning response might depend on inhibition of neutrophil adhesion, prevention, or both of cellular calcium overload. ${ }^{24}$ The 5 '-nucleotidase translocation increases the cellular adenosine production during prolonged ischemia and might confer protection by augmenting cellular energy stores, inhibiting leukocyte adherence, or both. ${ }^{25}$

Inflammatory cells are responsible for ischemic neuronal injury because these cells are found in the motor-injured area and either have a direct phagocyte effect or the secretion of cytokines, such as tumor necrosis factor $\alpha$, activates a signaling cascade that ultimately causes the upregulation of caspases and induces neuronal apoptosis. ${ }^{26}$ Our data clearly show that IPC spinal cord neuroprotection is found after a short reperfusion interval, suggesting a role of early IPC in the protection from neutrophil activation and neuronal apoptosis after a 120-hour follow-up.

Another observation of interest is that in the early IPC group 4, there was a significant reduction in proximal systolic arterial pressure and in heart rate during the second AOC of 35 minutes. This reduction was also noted in other studies ${ }^{17,23}$ and seems to be an ubiquitous effect of early IPC. A proposed explanation for this phenomenon has been given by Miyamoto and Miyamoto. ${ }^{27}$ They support the opinion that the effector of early IPC is the inhibitory and protective $\beta$-amino acid taurine, which has a half-life of more than 30 minutes in comparison with the 8-second half-life of the adenosine, and the long-lasting effects of taurine can explain the different hemodynamic profile during the second AOC in group 4.

In this study we investigated whether the early phase of IPC could be induced by means of brief AOC of the pig descending aorta, which is closer to clinical practice and offers more direct correlation to actual elective operative circumstance. This is the first study in the literature to evaluate the effect of early IPC against spinal cord injury in large mammals.

In our study it was of great importance to maintain the systolic arterial pressure at greater than $100 \mathrm{~mm} \mathrm{Hg}$ during the reperfusion interval of the 80 minutes between the 2 

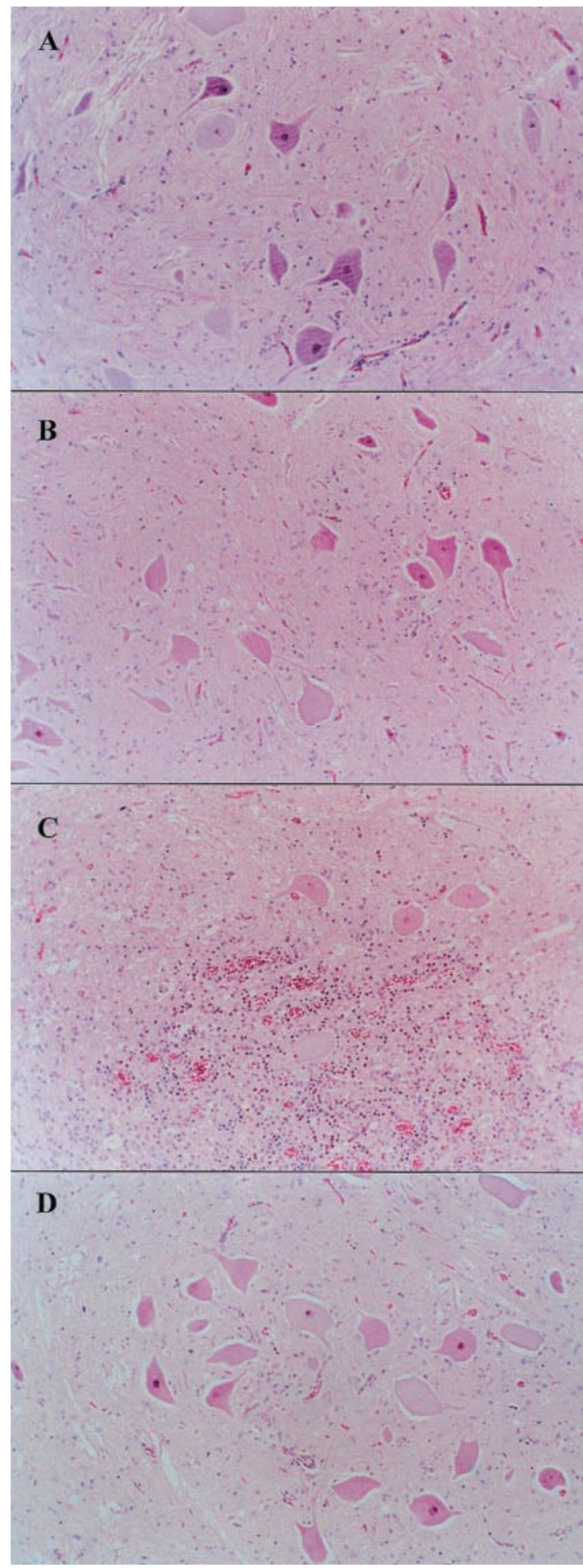

Figure 1. Representative photographs of lumbar spinal cord sections stained with hematoxylin and eosin. No neuronal damage to any motor neuron cells was found in animals of group 1 undergoing a sham operation (A), group 2 undergoing 20 minutes AOC (B), and the early IPC group 4 (D). 120 hours after 35 minutes of ischemia, approximately $60 \%$ of motor neuron cells in the gray matter were lost in the untreated group 3, whereas the inflammation is obvious (C). (Original magnification $330 \times$.)
AOCs in the early IPC group 4. Although having Tarlov scores of 4 at 24 hours, 2 excluded animals with systolic arterial pressures of 80 to $90 \mathrm{~mm} \mathrm{Hg}$ during this reperfusion interval became paraplegic at 48 and 120 hours (Tarlov score of 2 with the histologic evaluation, showing a loss of neurons and a moderate grade of inflammation). This finding is in accordance with the results of a clinical study by Griepp and coworkers. ${ }^{28}$ In their study they sequentially ligated pairs of the intercostal arteries that belonged to the aortic segment to be resected by maintaining high normal blood pressures, a procedure lasting 30 to 90 minutes. Their interpretation for the better neurologic outcome on behalf of the high normal blood pressure is that maintenance of high pressure during the sacrifice of the intercostal arteries allows collateral vessels to gradually assume the function of those severed and prevents steal phenomena from the anterior spinal artery. Their study is the first clinical report indicating that IPC of the spinal cord might have a protective effect on postoperative function.

If intention to treat is followed and all 10 animals are included in group 4, the 24-, 48-, and 120-hour Tarlov score difference in favor of group 4 is still statistically significant. However, it is well known that hypotension should be avoided during normothermic occlusion of the descending aorta, and our protocol specifically excluded experiments if hypotension was to occur.

In conclusion, our study demonstrates that early IPC after descending thoracic AOC in a porcine model prevents ischemic spinal cord injury, as evidenced by neurologic evaluation, and reduces it when tested on the basis of histopathology. This protection occurs when early IPC is followed with high normal arterial blood pressure.

We thank Mr Dimitrios Athanasoulas, RN, for his excellent technical assistance in preparing this experimental model.

\section{References}

1. Svensson LG, Crawford ES, Hess KR, Coselli JS, Safi HJ. Experience with 1509 patients undergoing thoracoabdominal aortic operations. $J$ Vasc Surg. 1993;17:357-68.

2. Estrera AL, Miller CC III, Huynh TT, Porat E, Safi HJ. Neurologic outcome after thoracic and thoracoabdominal aortic aneurysm repair. Ann Thorac Surg. 2001;72:1225-30.

3. Coselli JS, LeMaire SA, Conklin LD, Koksoy C, Schmittling ZC. Morbidity and mortality after extent II thoracoabdominal aortic aneurysm repair. Ann Thorac Surg. 2002;73:1107-16.

4. Safi HJ, Hess KR, Randel M, Iliopoulos DC, Baldwin JC, Mootha RK, et al. Cerebrospinal fluid drainage and distal aortic perfusion: reducing neurologic complications in repair of thoracoabdominal aortic aneurysm types I and II. J Vasc Surg. 1996;23:223-8.

5. Ross SD, Kron IL, Parrino PE, Shockey KS, Kern JA, Tribble CG. Preservation of intercostal arteries during thoracoabdominal aortic aneurysm surgery: a retrospective study. J Thorac Cardiovasc Surg. 1999;118:17-25.

6. McCullough JL, Hollier LH, Nugent M. Paraplegia after thoracic aortic occlusion: influence of cerebrospinal fluid drainage. Experimental and early clinical results. J Vasc Surg. 1988;7:153-60. 
7. Cambria RP, Davison JK. Regional hypothermia with epidural cooling for spinal cord protection during thoracoabdominal aneurysm repair. Semin Vasc Surg. 2000;13:315-24.

8. Kanellopoulos GK, Kato H, Wu Y, Dougenis D, Mackey M, Hsu CY, et al. Neuronal cell death in the ischemic spinal cord: the effect of methylprednisolone. Ann Thorac Surg. 1997;64:1279-85.

9. Agee JM, Flanagan T, Blackbourne LH, Kron IL, Tribble CG. Reducing postischemic paraplegia using conjugated superoxide dismutase. Ann Thorac Surg. 1991;51:911-4.

10. Acher CW, Wynn MM, Hoch JR, Popic P, Archibald J, Turnipseed WD. Combined use of cerebral spinal fluid drainage and naloxone reduces the risk of paraplegia in thoracoabdominal aneurysm repair. $J$ Vasc Surg. 1994;19:236-46.

11. Lang-Lazdunski L, Heurteaux C, Vaillant N, Widmann C, Lazdunski M. Riluzole prevents ischemic spinal cord injury caused by aortic crossclamping. J Thorac Cardiovasc Surg. 1999;117:881-9.

12. Parrino PE, Kron IL, Ross SD, Shockey KS, Fisher MJ, Gaughen JR $\mathrm{Jr}$, et al. Retrograde venous perfusion with hypothermic saline and adenosine for protection of the ischemic spinal cord. J Vasc Surg. 2000;32:171-8.

13. Cassada DC, Gangemi JJ, Rieger JM, Linden J, Kaza AK, Long SM, et al. Systemic adenosine A2A agonist ameliorates ischemic reperfusion injury in the rabbit spinal cord. Ann Thorac Surg. 2001;72:124550 .

14. Murry CE, Jennings RB, Reimer KA. Preconditioning with ischemia: a delay of lethal cell injury in ischemic myocardium. Circulation. 1986;74:1124-36.

15. Raeburn CD, Cleveland JC Jr, Zimmerman MA, Harken AH. Organ preconditioning. Arch Surg. 2001;136:1263-6.

16. Abraham VS, Swain JA, Forgash AJ, Williams BL, Musulin MM. Ischemic preconditioning protects against paraplegia after transient aortic occlusion in the rat. Ann Thorac Surg. 2000;69:475-9.

17. Zvara DA, Colonna DM, Deal DD, Vernon JC, Gowda M, Lundell JC. Ischemic preconditioning reduces neurologic injury in a rat model of spinal cord ischemia. Ann Thorac Surg. 1999;68:874-80.

18. Korthuis RJ, Gute DC, Cepinska G, Kvietys PR. Cellular mechanisms of acute versus delayed preconditioning. Pathophysiology. 1998;5:3548.

19. Pagliaro P, Gattullo D, Rastaldo R, Losano G. Ischemic preconditioning: from the first to the second window of protection. Life Sci. 2001;69:1-15.

20. Toumpoulis IK, Anagnostopoulos CE, Drossos GE, Malamou-Mitsi VD, Pappa LS, Katritsis DG. Does ischemic preconditioning reduce spinal cord injury because of descending thoracic aortic occlusion? $J$ Vasc Surg. 2003;37:426-32.

21. Tarlov IM. Spinal cord compression: mechanisms of paralysis and treatment. Springfield, Ill: Charles C. Thomas; 1957. p. 147.

22. Fan T, Wang CC, Wang FM, Cheng F, Qiao H, Liu SL, et al. Experimental study of the protection of ischemic preconditioning to spinal cord ischemia. Surg Neurol. 1999;52:299-305.

23. Ueno T, Chao ZL, Okazaki Y, Itoh T. The impact of ischaemic preconditioning on spinal cord blood flow and paraplegia. Cardiovasc Surg. 2001;9:575-9.

24. Ishida T, Yarimizu K, Gute DC, Korthuis RJ. Mechanisms of ischemic preconditioning. Shock. 1997;8:86-94.

25. Carden DL, Granger DN. Pathophysiology of ischaemia-reperfusion injury. J Pathol. 2000;190:255-66.

26. Neumar RW. Molecular mechanisms of ischemic neuronal injury. Ann Emerg Med. 2000;36:483-506.

27. Miyamoto TA, Miyamoto KJ. Mechanisms of acute ischemic preconditioning. Ann Thorac Surg. 2000;70:2186.
28. Griepp RB, Ergin MA, Galla JD, Lansman S, Khan N, Quintana C, et al. Looking for the artery of Adamkiewicz: a quest to minimize paraplegia after operations for aneurysms of the descending thoracic and thoracoabdominal aorta. J Thorac Cardiovasc Surg. 1996;112: 1202-13.

\section{Discussion}

Dr Ludwig K. von Segesser (Lausanne, Switzerland). Could you be more precise about your experimental model? I did not fully understand whether you vented the excluded segment of the aorta and let the blood come out there, or if you had the excluded segment perfused by collateral blood coming from the intercostals.

Dr Anagnostopoulos. There was no venting and no perfusion, and I remind you that the balloons are rather long. Therefore, there was actually occlusion of about 3 or 4 pairs of intercostals high up (ie, T5, T6, T7, or T8) and the lower one down. But there was no venting in between.

Dr Henry M. Spotnitz (New York, NY). Was there complete $\mathrm{AOC}$ at that level or only occlusion of the intercostals?

Dr Anagnostopoulos. Yes, there was. The balloons become sausagelike when inflated, and they occlude the aorta completely. They will go up and down as they inflate more and more. Therefore, there was no dye going through.

Dr Spotnitz. Was there hypertension when the balloon was inflated?

Dr Anagnostopoulos. Proximally, yes, and we have that in the article. Pressure rose to 150 or $170 \mathrm{~mm} \mathrm{Hg}$.

Dr Spotnitz. The period of time you used for preischemic conditioning was 20 minutes. That seems like a long time and conceivably could result in spinal cord injury. Could you comment on that?

Dr Anagnostopoulos. I meant to justify the time because, as I had presented in the pre-existing small-animal experiments, the time was much less. We had a number of experiments, particularly in our other work, showing that there was no reduction in the number of cells, no inflammatory changes, no score change in the histopathology that we could detect at that point, at 20 minutes, and we already had that knowledge that it was not a negative test.

Dr Frank W. Sellke (Boston, Mass). Is the mechanism of spinal cord preconditioning the same as in the myocardium? Is it due to the opening of $\mathrm{K}_{\mathrm{ATP}}$ channels or activation of protein kinase C? Could you use adenosine or some $\alpha$-adrenergic agonist to do pharmacologic preconditioning, which might be more applicable clinically?

Dr Anagnostopoulos. I know you have not read the article yet, but we think that is true. Not to belabor the point, because I am not an expert on the future, but I think there are other laboratories that are using adenosine. Our intention was to find an experimental model that works trying to define this business that Dr Spotnitz mentioned, 20 minutes, the preconditioning, and to define the 35 minutes so maximal changes can be shown. 